\title{
Referrals for coronary angiography in a high risk population
}

\author{
Frank Kee
}

\begin{abstract}
Objectives-To examine variations in referral for coronary angiography within Northern Ireland and relate these to local death rates from coronary artery disease (ICD rubrics 410-414).

Design-A descriptive retrospective analysis of aggregate hospital activity data for 1979-88 and corresponding mortality rates in the local population.

Setting-Two regional referral hospitals and 26 local district council areas.

Patients-5173 patients aged 35-74 years with an underlying diagnosis of ischaemic heart disease, whose records contained complete information on their age, sex, and home address.
\end{abstract}

Main measures-Age-standardised angiography rates and corresponding standardised death rates derived from the registrar general's reports.

Results-Among the 26 constituent district council areas there was significant heterogeneity in the angiography rates, ranging from 62 to $335 / 100000$ in men and from 7 to $62 / 100000$ in women (likelihood ratio statistic 856 and 359 respectively). There was no significant association between these angiography rates and the local death rates from ischaemic heart disease.

Conclusion-The results suggest a nonuniform threshold for referral for angiography.

Implications-Clinicians need to examine the appropriate indications for referral for invasive investigation.

(Quality in Health Care 1993;2:87-90)

\section{Introduction}

In the past 30 years many advances in coronary care have been pioneered in Northern Ireland. Although resources are rightly channelled into continued primary prevention programmes, a strategically focused approach that combines prevention with appropriate intervention will probably deliver maximum health gain. ${ }^{1}{ }^{2}$ Therefore it is important for cardiological and surgical services to be balanced in the most efficient manner. ${ }^{3}$ In the United States there continues to be debate about the appropriate indications for coronary angiography, ${ }^{4}$ but physicians' attitudes towards the diagnosis and treatment of coronary heart disease seem to be more conservative in the United Kingdom. ${ }^{5}$ Over the past 10 years the number of invasive cardiological assessments performed has grown substantially, ${ }^{6}$ but there is scant information on how geographical variations in mortality relate to variations in referrals for angiography and revascularisation.

Although Northern Ireland has the highest death rate from ischaemic heart disease in the United Kingdom, there is significantly heterogeneity in mortality throughout the province. Geographical variations in mortality have been used widely as proxies for disease prevalence. ${ }^{7}$ Indeed, data from the regional heart study indicate a strong correlation between mortality and prevalence of coronary heart disease. It has been estimated that for a $10 \%$ variation in mortality there is a $15.6 \%$ difference in morbidity. ${ }^{8}$

The objective of this study was to describe the variations in referrals for coronary angiography and relate these to the mortality from coronary heart disease in the 26 constituent district council areas of Northern Ireland.

\section{Methods}

Northern Ireland has only two centres for invasive cardiological assessment, at the Royal Victoria and the Belfast City hospitals. These hospitals are situated only $1.6 \mathrm{~km}$ ( 1 mile) apart in Belfast, and they receive referrals for invasive assessment from all over the province. Data on all patients (aged 35-74 years) undergoing coronary angiography (Office of Population Censuses and Surveys IV) (OPCS IV) code K63: "contrast radiology of the heart") who had an underlying diagnosis of ischaemic heart disease (ICD 410-414) were obtained from the Hospital Activity Analysis files submitted by the two hospitals to the Department of Health and Social Services. The age, sex, and district council of residence was abstracted for each patient, and the number of procedures was aggregated for the 10 years between 1979 and 1988. The population structure of the 26 district council areas varies, some of the coastal regions having relatively larger "retirement" communities. Directly age-standardised angiography rates were derived for each district council area for all patients aged 35-74 years, with the Northern Ireland population as the standard. These rates were then compared with the standardised death rates for ischaemic heart disease (ICD 410-414) for the same areas.

Because of the range in population size of the district councils (for example, Belfast, the largest, has 295223 residents and Moyle, the smallest has 14252 ), Poisson regression was used to test whether significant heterogeneity existed in the angiography rates. The death
Frank Kee, consultant

Accepted for publication 23 March 1993 

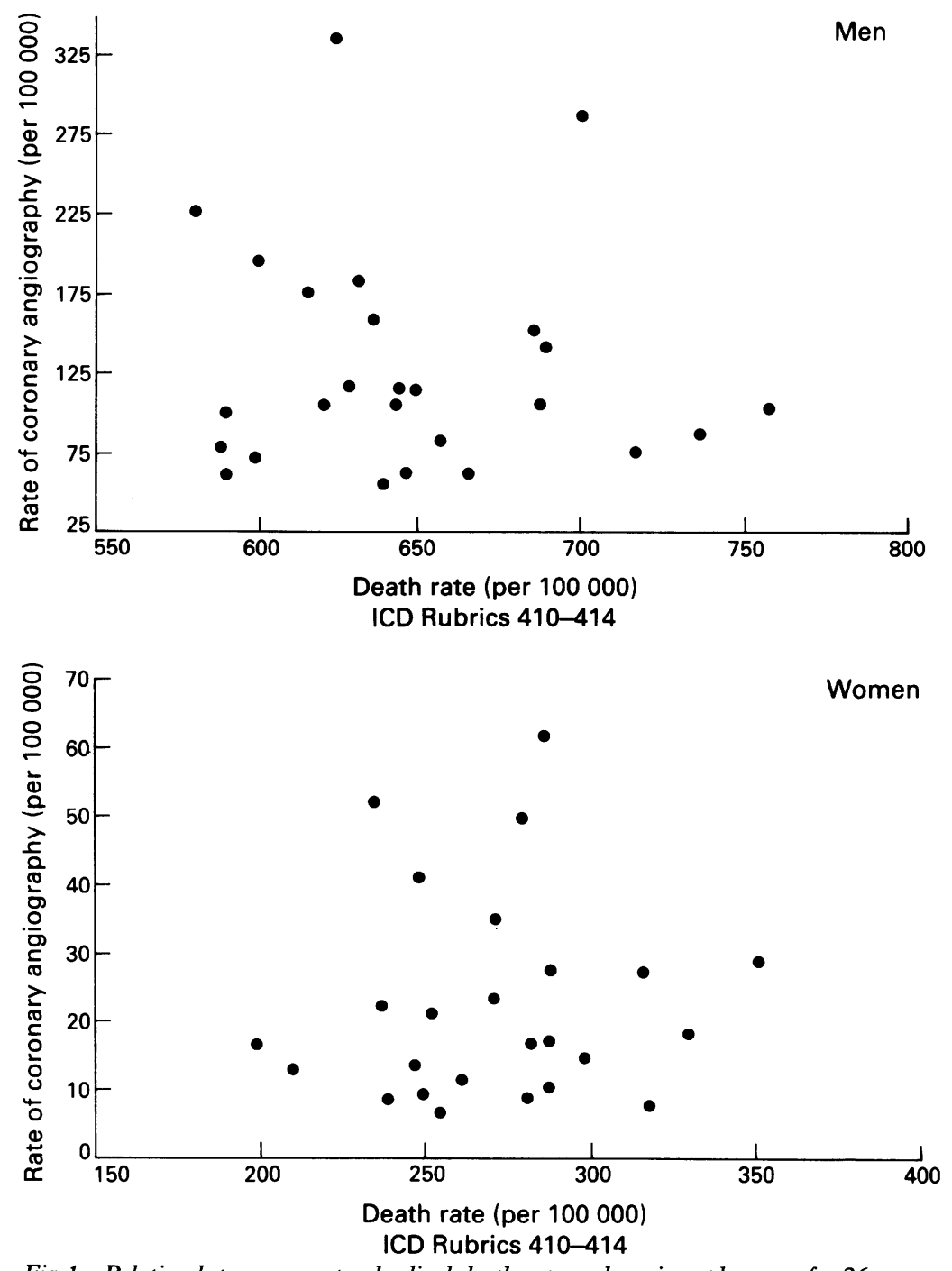

Fig 1 Relation between age-standardised death rate and angiography rates for 26 district council areas in Northern Ireland, 1979-88

rates and rates of angiography were compared with Spearman's correlation test to compare ranks. The analysis was carried out with EGRET software.

\section{Results}

During 1979-88 the Hospital Activity Analysis files had records of 7662 patients undergoing angiography, of whom 5173 had been given an underlying diagnosis of ischaemic heart disease. For these 5173 records, the patient's district council of residence was known. There was no information available for the complete study period on the number of records in

Districts ranking highest and lowest for angiography and death rates from coronary causes, 1979-88

\begin{tabular}{|c|c|c|c|c|}
\hline \multirow[t]{2}{*}{ Rank } & \multicolumn{2}{|c|}{ Men } & \multicolumn{2}{|c|}{ Women } \\
\hline & Rate of referral & Death rate & Rate of referral & Death rate \\
\hline $\begin{array}{l}1 \\
2 \\
3 \\
4 \\
5\end{array}$ & $\begin{array}{l}\text { Carrickfergus } \\
\text { Newtownabbey } \\
\text { Belfast } \\
\text { Fermanagh } \\
\text { Lisburn }\end{array}$ & $\begin{array}{l}\text { Derry } \\
\text { Cookstown } \\
\text { Coleraine } \\
\text { Newtownabbey } \\
\text { Omagh }\end{array}$ & $\begin{array}{l}\text { Newtownabbey } \\
\text { Belfast } \\
\text { Carrickfergus } \\
\text { Lisburn } \\
\text { Fermanagh }\end{array}$ & $\begin{array}{l}\text { Larne } \\
\text { Derry } \\
\text { Ballymoney } \\
\text { Craigavon } \\
\text { Dungannon }\end{array}$ \\
\hline $\begin{array}{l}22 \\
23 \\
24 \\
25 \\
26\end{array}$ & $\begin{array}{l}\text { Castlereagh } \\
\text { Limavady } \\
\text { Ballymena } \\
\text { Ballymoney } \\
\text { Moyle }\end{array}$ & $\begin{array}{l}\text { Castlereagh } \\
\text { North Down } \\
\text { Ballymoney } \\
\text { Magherafelt } \\
\text { Belfast }\end{array}$ & $\begin{array}{l}\text { Moyle } \\
\text { Banbridge } \\
\text { Coleraine } \\
\text { Ballymoney } \\
\text { Limavady }\end{array}$ & $\begin{array}{l}\text { Coleraine } \\
\text { Ards } \\
\text { Belfast } \\
\text { Castlereagh } \\
\text { North Down }\end{array}$ \\
\hline
\end{tabular}

which the patient's address was unknown, but in recent years this has been less than 5\%. Thus this analysis is based on the 5173 records in which the patient's age, sex, and address were known. Although there was no direct way to validate the completeness of the Hospital Activity Analysis files, there was no reason to suppose that records of residents of any specific district council would have been more or less likely to have gone uncoded.

The primary result of this study is a description of the relation between the average annual age-standardised angiography rates and death rates for the 26 district council areas in the province (summarised in figure 1). There was a greater than fivefold variation in the referral rates among men (55-335/100 000) and an eightfold range among women (7-62/100 000). Among men only one of the five districts with the highest angiography rates was among the top five with the highest death rates, and this pattern was also observed for women; conversely only one district among the five with the lowest angiography rates appeared among the five with the lowest death rates (table). The variation in angiography rates among district councils was highly significant, the likelihood ratio statistics in the Poisson regression model being 856 and 359 for men and women respectively, after fitting separately a term for age $(p<0.001$, $\mathrm{df}=25$ ).

The correlation coefficients between the angiography rates and death rates for these 26 district council areas were -0.07 (SE 0.2 , $\mathrm{p}>0.05)$ and 0.09 (SE 0.2, p > 0.05) for men and women respectively. Of note is the absence of any significant association between death rates and angiography rates for either men or women.

Among the district councils there was a positive (though not significiant) association between the death rates of men and women (correlation coefficient $0 \cdot 29$, SE $0 \cdot 19$, $p>0.05$ ), but the rates of angiography for men and women were highly correlated (coefficient $0 \cdot 84$, SE $0 \cdot 11, \mathrm{p}<0.001$ ). Figure 2 illustrates this pattern of association.

\section{Discussion}

This study showed that there is very little relation between angiography rates and mortality from coronary heart disease among the 26 district councils in Northern Ireland. The province is host to one of the World Health Organisation's projects on monitoring trends and determinants in cardiovascular disease (MONICA) and from the project data it is known that area mortality within the province is a relatively good proxy for incidence of infarction. Given a uniform threshold for referral, areas with high death rates might be expected to have correspondingly high rates of angiography. The absence of such an association could have several explanations.

It might be argued that those areas with the highest angiography rates also had the populations which received relatively more cardiac surgery. This would tend to reduce the death rate for some people, thus rather than local 


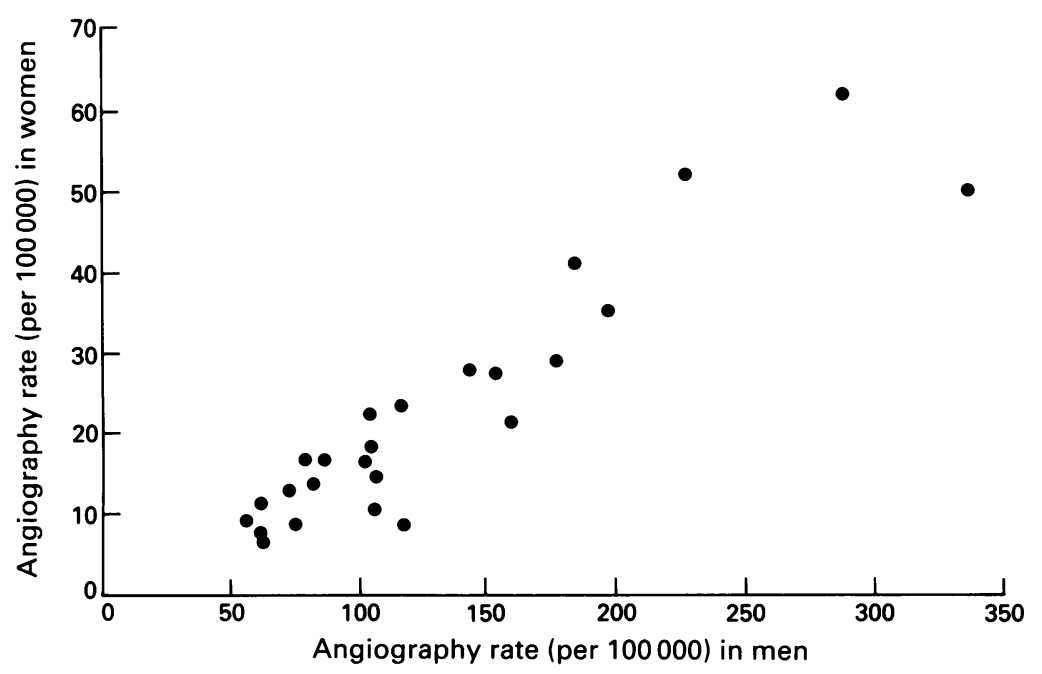

Fig 2 Relation between age-standardised angiography rates in men and women in 26 district council areas in Northern Ireland, 1979-88 association between men and women for angiography rates than for death rates among the district council areas.

Referrals for coronary angiography can be made either directly by general practitioners (predominantly in the greater Belfast areas) to cardiologists in one of the two "regional" centres or through physicians and cardiologists practising at peripheral hospitals. An alternative and more likely explanation for the patterns observed would be that there is a non-uniform threshold for referral for angiography. From reports predominantly from the United States it seems that differences in referral patterns for angiography can result in certain patient groups having greater access to revascularisation. ${ }^{12-17}$ In Scotland there are major differences in the rates of angiography in neighbouring health boards, with rates tending to be higher in boards with angiographic facilities and in areas of low material deprivation. ${ }^{16} 17$ Clearly then, under-referral may create inequitable provision of revascularisation services especially if cardiac surgery contracts are established with an eye to existing waiting list statistics.

For all of the district council areas studied the ratio of male to female death rates was less than the corresponding ratio for angiography. Across the province as a whole these ratios were $2 \cdot 5: 1$ and $5: 1$ respectively. This may reflect some relative under-referral of women and, if so, would concur with other studies. ${ }^{13-15}$ The results from these studies have not been entirely consistent, however. One study showed that among patients undergoing angiography women had significantly lower rates of severe stenoses and that after adjustment for this the rates of angiography in men and women were comparable. ${ }^{15}$ Another study reported that despite women having more severe symptoms and greater functional disability men were twice as likely to have an invasive investigation. ${ }^{13} \mathrm{~A}$ more detailed appraisal of case mix and severity would be required to confirm whether this was the case in Northern Ireland. In the largest study in the United States the authors remind us that it is difficult to distinguish underuse by women from overuse by men. ${ }^{14}$ In view of the relative lack of consensus on the ability to predict those patients likely to experience adverse events, ${ }^{18}{ }^{19}$ local clinicians may do well to examine (perhaps through medical audit ${ }^{20}$ ) their own thresholds for referral for angiography to ensure that scarce revascularisation resources are being distributed to maximum benefit in the community. of disease, some areas may have a smaller pool of patients eligible for referral. There is little direct evidence for comment on this hypothesis. The only local study of its kind compared incidence and mortality in Ballymena and Omagh district council areas and found a $13 \%$ lower mortality in Ballymena, which, unlike Omagh, had access to mobile coronary care. ${ }^{11}$ However, in the present study the average annual referral rates in Omagh were more than twice those for the population of Ballymena (142 $v 62$ in men and $28 v 12$ in women). This argument is also hard to sustain in light of the much stronger
1 Varnauskas E. European Coronary Study Group. Twelve year follow up of survival in the randomised European coronary surgery study. $N$ Engl $\mathcal{F}$ Med 1988;319:332-7.

2 Yorkshire Regional Health Authority and Faculty of Public Health Medicine. Implementing "Health of the nation". An example: ischaemic heart disease. Harrogate: Yorkshire Regional Health Authority and the Faculty of Public Health Medicine, 1992.

3 Provision of services for the diagnosis and treatment of heart disease. Fourth report of a joint cardiology and the Royal College of Surgeons of England. $\mathrm{Br}$ Heart $\mathcal{f}$ 1992;67:106-16. committee of the Royal College of Physicians of London 
4 Chassin MR, Kosecoff J, Solomon DH, Brook RH. How coronary angiography is used. Clinical determinants of appropriateness. FAMA 1987;258:2543-7.

5 Brook RH, Kosecoff J, Park RE, Chassin MR, Winslow C, Hampton JR. Diagnosis and treatment of coronary disease: comparison of doctors in the USA and the UK. Lancet 1988;i:750-3.

6 MacRae CA, Marber MS, Keywood C, Joy M. Need for invasive cardiological assessment and intervention: a ten year review. Br Heart f 1992;67:200-3.

7 Palmer S, West P, Patrick D, Glynn M. Mortality indices in resource allocation. Community Med 1979;1: in resour

8 Jadavji S, Craig N, Atherton J, Mordue A, Bailes S. The need for coronary artery bypass grafts. Newcastle upon Tyne: Northern Regional Health Authority,

9 Review of adult cardiology services in the Eastern Health and Social Services Board. A report of a working group. Belfast: EHSSB, 1988. (Badenoch report.)

10 Alderman E, Bourassa M, Cohen LS, et al. Ten year follow up of survival and myocardial infarction in the randomised coronary artery surgery study. Circulation 1990;82:1629-46.

11 Mathewson ZM, McCloskey BG, Evans AE, Russell CJ, Wilson C. Mobile coronary care and community mortality from myocardial infarction. Lancet 1985; i: $441 \cdots 4$.
12 Elder AT, Shaw TRD, Turnbull CM, Starkey IR. Elderly and younger patients selected to undergo coronary angiography. BMF 1991;303:950-3.

13 Steingart RM, Packer M, Hamm P, Coglianese ME, Gersh $\mathrm{B}$, Geltman E, et al. Sex differences in the management of coronary artery disease. $N$ Engl Med $f$ 1991;324:226-30.

14 Ayanian JZ, Epstein AM. Differences in the use of procedures between women and men hospitalised for coronary disease. $N$ Engl Med $\mathcal{f}$ 1991;325:221-5.

15 Kromholz H, Douglas P, Lauer M, Pasternak R. Selection of patients for coronary angiography and coronary of patients for coronary angiography and coronary evidence for a gender bias? Ann Intern Med evidence for a

16 Findlay IN, Dargie HJ, Dyke T, Archibald M. Who gets coronary angiography in Scotland? Br Heart $\mathcal{f}$

17 Findlay IN, Dargie HJ, Dyke T. Coronary angiography in Glasgow: relation to coronary heart disease and social class. Br Heart 7 1991;66:70.

18 Bodenheimer $M$. Risk stratification in coronary disease: a contrary viewpoint. Ann Intern Med 1992;116:927-36.

19 Patterson DLH, Treasure T. The culprit coronary artery lesion. Lancet 1991;338:1379-80.

20 Gray D, Hampton J, Bernstein S, Kosecoff J, Brook R. Audit of coronary angiography and bypass surgery. Lancet 1990;335:1317-20. 